\title{
The Me and My Disease Scale: measuring state hope and determining its impact on coping in patients with type 2 diabetes mellitus and myocardial infarction
}

\section{BACKGROUND}

The aim of this study was to examine the psychometric properties, factor structure, measurement invariance, internal consistency reliability and construct validity of the Me and My Disease Scale - a tool for state hope measurement for adults suffering from chronic medical conditions.

\section{PARTICIPANTS AND PROCEDURE}

Two clinical groups, patients with type 2 diabetes (DM) $(n=278)$ just before and 1 month after introducing insulin treatment, and cardiac patients $(n=232)$ five days and one month after their first uncomplicated myocardial infarction (MI), participated in the study. Cognitive appraisal, emotions and depression (MI group) were measured to establish the construct validity of the scale.

\section{RESULTS}

A single-factor model which consisted of 4 items was established. The structure was characterized by good measurement model fit and satisfactory indicators of reli- ability for the MI subgroup. A less satisfactory model fit was obtained for the DM subgroup - this may point to the impact of specific medical conditions on the scale. Furthermore, the findings indicated metric invariance for the scale. The moderate correlations between hope and cognitive appraisal, emotion and depression confirm the construct validity of the scale.

\section{CONCLUSIONS}

The Me and My Disease Scale is characterized by satisfactory psychometric parameters and can be used in scientific research to measure hope as a dimension of cognition and to compare the relationships between hope and other variables in medical patients. However, caution should be taken during analysis when comparing means between clinical groups.

\section{KEY WORDS}

factor analysis; construct validity; measurement invariance; state hope scale 
It is a peculiarity of man that he can only live by looking to the future - sub specie aeternitatis. And this is his salvation in the most difficult moments of his existence, although he sometimes has to force his mind to the task. Viktor Frankl, 1984, p. 94

\section{BACKGROUND}

Zuzanna

Kwissa-Gajewska, Aleksandra Kroemeke, Irena Heszen

The psychiatrist Viktor Frankl describes hope as a specifically human trait: the ability to look forward to the future and to plan for it. Researchers who have examined stress have defined hope as a resource which can be drawn on during difficult situations, such as illnesses, when hopelessness can have significant negative consequences (see Folkman, 2010). Despite recent challenges to the position that psychological factors can influence survival rates, for example in patients suffering from breast cancer (Coyne, Stefanek, \& Palmer, 2007), it is generally maintained that hope can improve psychological functioning and overall quality of life for people who are coping with chronic disease - a source of stress with varying intensity (Heszen, 2012).

When measuring the efficacy of hope, it is important to take into account the individual context and life situation of each patient. Lazarus and Folkman's prominent stress model includes positive emotions rooted in cognitive assessment (Folkman \& Lazarus, 1985), and academic interest in the positive aspects of stress has increased since research into caregivers for AIDS patients (Folkman, 1997). It has been demonstrated that people in difficult life situations experience both negative and positive emotions. This has resulted in modifications to theoretical models of stress and coping and increased exploration of the sources and roles of positive emotions for individuals under stressful conditions (Folkman, 2008), and hope has been shown to have particular significance (Lazarus, 1999; Folkman, 2010). Hope has a cognitive basis which includes "emotional tones" (Folkman, 2010). Lazarus $(1999,2006)$ defines hope as a psychological resource, a conviction that improvement is possible, and as yearning for positive results. As such, hope emerges when life conditions are unsatisfactory or threatening, for example after the diagnosis of a chronic disease and its intensity, and its dynamism and valence depend on cognitive assessment and situational context (Folkman, 2010). Therefore, hope cannot be defined as an entirely positive phenomenon (Lazarus, 1991). To have positive valence, hope requires an appraisal of a situation as supportive or goal-congruent (challenge appraisal; Lazarus, 1991).

There is a two way relationship between hope and coping. Hope can sustain coping efforts (given that it contains information and goals) and, in turn, hope is reinforced by coping (Folkman, 2010). Folkman (2010) compares hope to the calming effect of emotion-focused coping strategies and argues that hope has a broader, more existential meaning. This assertion partly draws on Snyder's concept of dispositional hope (Snyder et al., 1996). Snyder (2002) defines hope as an individual's capacity to achieve goals (agency) as well as to plan to reach those aims (pathways), which, as Snyder points out, plays an important role in psychological adjustment - hope is conceptualized here as cognition. Other researchers present the contrasting view that hope is an emotion or a state with an emotional component (Bruininks \& Malle, 2005; for review see Tong, Fredrickson, Chang, \& Lim, 2010).

If hope can play a significant role in coping with stress and adapting to difficult situations, it should be taken into account when studying stress. Therefore, measuring hope emerges as an important issue for studying stress. However, the authors of the transactional stress model rarely included hope in their own studies - although they did analyse its theoretical status in the stress model - and they did not construct a tool to measure hope (only a single item for "hopeful" was classified as a "challenge emotion" in the Stress Questionnaire; Folkman \& Lazarus, 1985). Most studies on the role of hope in adapting to difficult situations have applied Snyder's Adult Dispositional Hope Scale (DHS), a 12-item scale measuring hope as a disposition (Snyder et al., 1991), or the State Hope Scale, a 6-item scale measuring hope as an emotional state (Snyder et al., 1996). Both questionnaires consist of agency and pathways subscales. Other tools for measuring hope in the context of illness include the Visual-Analogue Scale (VAS) for terminal cancer (Rabkin, McElhiney, Moran, Acree, \& Folkman, 2009) and the Gottschalk-Gleser Content Analysis Scale, which is used for three medical conditions (Heszen-Niejodek, Gottschalk, \& Januszek, 1999).

Studies taking into account hope as a disposition demonstrate that it has a significant influence on cognitive appraisal (Chang \& DeSimone, 2001), level of stress reactivity (Ong, Edwards, \& Bergeman, 2006), coping style (Hasson-Ohayon, Braun, Galinsky, \& Baider, 2009), coping strategy use (Drach-Zahavy \& Somech, 2002; Stanton, Danoff-Burg, \& Huggins, 2002; Roesch, Duangado, Vaughn, Aldridge, \& Villodas, 2010), adjustment in the form of post-traumatic stress disorders as well as post-traumatic growth (Ai, Tice, Whitsett, Ishisaka, \& Chim, 2007), physical fatigue (Ai, Wink, \& Shearer, 2012), distress (Ai, Park, Huang, Rodgers, \& Tice, 2007) and depression (Hassija, Luterek, Naragon-Gainey, Moore, \& Simpson, 2012). In addition, state hope was positively related to coping strategies (fighting spirit; Kennedy, Evans, \& Sandhu, 2009) and positive affect (Steffen \& Smith, 2013), and it correlated negatively with negative emotions (Ong et al., 2006). Recently, hope and its consequences have been the subject of numerous qualitative studies carried out on patients with vari- 
ous diseases such as terminal illness (Gum \& Snyder, 2002), myocardial infarction (Kristofferzon, Löfmark, \& Carlsson, 2008) and neurological disorders (Soundy et al., 2011).

\section{RESEARCH PROBLEMS}

All of the above mentioned methods for measuring hope are either generic and thus apply to a relatively constant set of reactions to difficult situations or they lack specificity in terms of context. Given that hope emerges during serious threats (see Lazarus, 1999) and taking into account the transactional model of stress, the Me and My Disease Scale was constructed to measure hope which incorporates the context of somatic illness. The assumption was that hope, like other psychological constructs, could be approached as both a disposition and an actual psychological state. In this study hope is defined as a state, namely the state of expecting goal realisation in an uncertain or extremely threatening situation and expecting positive outcomes regardless of personal situation. This concept of hope draws on Snyder's cognitive approach.

Initially, for the construction of the scale, twelve statements were generated related to hope in terms of anticipating achievements and health improvements based on the other scales which measured hope. On the basis of critical semantic analysis, redundant statements were rejected. Afterwards, a pilot version of the scale was made. This consisted of ten statements (see Table 2) which were adjusted to measure hope during the experience of illness and accorded to the hope as state definition.

The main goal of the statistical analysis was to assess the factor validity of the original questionnaire in order to measure state hope. This was done using explorative and confirmative factor analysis. Attention was paid to reliability and construct validity. Scale characteristic studies were carried out with two groups of patients: a group of individuals after their first myocardial infarction (MI) and another group with type 2 diabetes (DM) requiring insulin therapy. Myocardial infarction and DM are different in terms of their course and present opposite temporal patters when it comes to the levels of stress experienced by the patients (see Heszen, 2012). This enabled analysis which described the structure of the tool in both the entire clinical group and in the two subgroups (MI and DM). It also allowed for an assessment of measurement invariance (i.e. whether it varies depending on the specificity and the stressfulness specific to certain situations). Tests for internal consistency and test-retest assessments were also carried out. Construct validity was examined according to Lazarus and Folkman's theory by showing relationships between state hope and indicators of coping: cognitive appraisal, coping strategies and emotional state (emotions and depressive symptoms) (Folkman \& Lazarus, 1985). A negative correlation was anticipated between hope and threat/loss cognitive appraisal, negative emotions and depression, whereas a positive correlation was expected for challenge cognitive appraisal and positive emotions. In addition, the context dependency of state hope was tested. It was hypothesized that a change in health situation accompanied by stress would lead to an intensification of hope. In the case of DM patients after initiating insulin therapy, this was expected to lead to an increase in stress due to a growing awareness of the progression of the illness and demands associated with the treatment. In turn, this would decrease the patient's level of hope. An opposite reaction was expected in MI patients. Here the main stressor, the risk of death, decreases a month after the incident. This was expected to increase levels of hope.

\section{PARTICIPANTS AND PROCEDURE}

\section{METHODS}

The sample comprised 278 patients with DM and 232 cardiac patients after their first uncomplicated MI. Both groups were assessed twice: patients with DM just before being informed by the physician that they would begin insulin treatment (Time 1 [T1], $n=305)$ and subsequently one month later (Time 2 [T2], $91.10 \%$ of the original sample). Cardiac patients were assessed five days after MI (T1, $n=252)$ and one month later (T2, $92.10 \%$ of initial sample). Missing data for both groups were random according to Little's MCAR test $\left(\chi^{2}(127)=117.02, p=.726, \chi^{2}(115)=\right.$ $=116.09, p=.454$, for DM and MI group respectively).

After obtaining informed consent, participants completed questionnaires assessing cognitive appraisal, state affect and hope as well as depression symptoms (only cardiac group). The study was approved by the ethics committee. The main socio-demographic characteristics of the groups, characteristics of main variables and the comparisons between groups (ANOVA) and phases (MANOVA) are shown in Table 1.

As expected, there were differences between the groups in terms of indicators of coping activity (cognitive appraisal, affect, symptoms of depression) due to a different course of the illnesses: MI patients experienced decreasing coping activity as the risk of death ceded and DM patients experienced more with the worsening of their life situation.

\section{VARIABLES}

State hope. State hope was measured by the 10 -item pilot version of the scale. Each statement was re-
The Me and My Disease Scale: measuring state hope 
Table 1

Characteristics of the samples, main variables and the comparisons between groups (ANOVA) and phases (MANOVA)

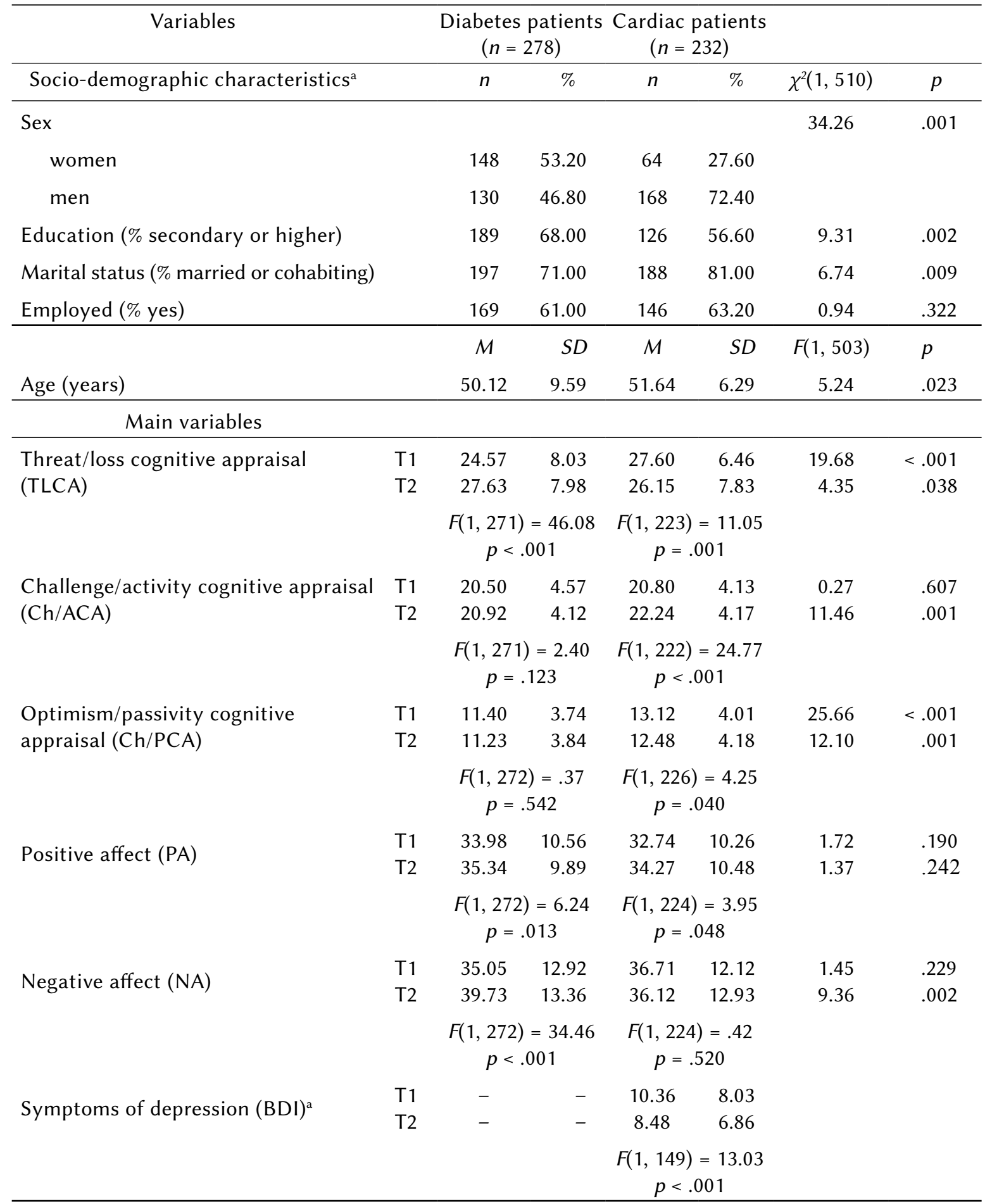

Note. T1 and T2 - time 1 and 2 respectively.

${ }^{\mathrm{a}} \mathrm{N}=150$.

sponded to with a five-point Likert scale with answers ranging from "strongly disagree" to "strongly agree" (see Table 2). Higher scores indicate a higher intensity of hope.

Positive and negative emotions. Positive affect (PA) and negative affect (NA) were assessed with the Positive and Negative Affect Schedule (PANAS) by Watson, Clark, and Tellegen (1988) using a Polish adaptation by Brzozowski (2010). Originally both scales consisted of 15 adjectives (e.g., "enthusiastic", "active", "nervous", "guilty", etc.) but in this particular study a 12 -item scale was used ${ }^{1}$. The participants 
Table 2

Results of exploratory factor analysis of the ten items in the Me and My Disease Scale

\begin{tabular}{|c|c|c|c|c|}
\hline \multirow[t]{2}{*}{ Item } & \multirow[t]{2}{*}{ Question } & \multicolumn{3}{|c|}{ Factor loadings } \\
\hline & & $\begin{array}{l}\text { Entire } \\
\text { sample }\end{array}$ & Diabetic & Cardiac \\
\hline 1 & I have many plans for the future & .641 & .698 & .635 \\
\hline 2 & My goals are very likely to be achieved & .660 & .743 & .590 \\
\hline 3 & I search for additional ways that may lead to my recovery & .455 & .445 & .522 \\
\hline 4 & $\begin{array}{l}\text { I believe that there are many different ways that may lead to } \\
\text { my recovery }\end{array}$ & .592 & .648 & .490 \\
\hline 5 & $\begin{array}{l}\text { I am confident that my chances of recovery are higher than } \\
\text { those of an average person suffering from the same condition }\end{array}$ & .628 & .621 & .545 \\
\hline 6 & $\begin{array}{l}\text { I know I will be able to avoid health complications attached to } \\
\text { my illness and the recovery process }\end{array}$ & .630 & .651 & .554 \\
\hline 7 & $\begin{array}{l}\text { My illness is going to lead to positive changes in my personal } \\
\text { life }\end{array}$ & .573 & .529 & .517 \\
\hline 8 & I believe that I will get well & .662 & .712 & .527 \\
\hline 9 & Regardless of my illness, I will achieve my goals & .674 & .716 & .659 \\
\hline \multirow[t]{2}{*}{10} & There is a high chance that I will get well & .760 & .752 & .723 \\
\hline & $\%$ of variance & 39.94 & 43.30 & 33.70 \\
\hline
\end{tabular}

rated the extent to which they felt each of the 24 emotions was relevant to their experience on a five-point Likert scale. At every stage and in both groups, positive and negative affect were independent from each other. Cronbach's $\alpha$ coefficients ranged from .89 (PA for both groups at T2) to .96 (NA for the DM group at T2).

Cognitive appraisal. Cognitive appraisal was assessed with the Stress Appraisal Questionnaire (Włodarczyk \& Wrześniewski, 2010). This measures cognitive appraisal in terms of Lazarus' theory. The scale consists of 35 items describing how people might perceive a specific stressful situation. Three subscales were identified: threat/loss (e.g. "This situation was terrifying”), challenge/activity (e.g. "This situation was mobilizing") and optimism/passivity cognitive appraisal (e.g. "This situation was promising”). Cronbach's $\alpha$ coefficients ranged from .75 (challenge/passivity appraisal for the DM group at T2) to .93 (threat/loss appraisal for the DM group at T2).

Depression. A number of symptoms of depression in cardiac patients were assessed using the Beck Depression Inventory (BDI) by Beck, Ward, Mendelson, Mock, and Erbaugh (1961) - Polish adaptation by Parnowski and Jernajczyk (1977) $(\alpha=.87$ and .86 at $\mathrm{T} 1$ and T2, respectively). Participants rated the frequency of the occurrence of one of 21 depression symptoms during the past week ranging from $0=$ "less than one a day" to $3=$ "most of the time ( 5 to 7 days)".

\section{STATISTICAL ANALYSIS}

In order to test dimensional structure, exploratory factor analysis (EFA) and confirmatory factor analysis (CFA) were performed taking maximum likelihood (ML) estimates by means of analysis of moment structures (AMOS 20) and the Standard Error Scree Test (Watkins, 2007). To examine the equivalence of the model across subgroups and phases (measurement invariance) multi-group comparisons were tested (AMOS 20). Further analysis of internal consistency, test-retest reliability as well as validity and situational context dependency of state hope were conducted using IBM SPSS 20.0.

\section{RESULTS}

\section{EXPLORATORY FACTOR ANALYSIS}

In order to establish the factor structure of the questionnaire, EFA with principal axis, extraction and varimax rotation was performed using responses from the first phase of the study [T1] - this was done for the entire sample as well as for each of the subgroups (MI vs. DM).

In order to determine the number of factors, the Kaiser-Guttman rule (Zakrzewska, 1994) was used: the numbers of factors are equal to the number of eigenvalues $>1$. This indicated the plausibility of three factors. In addition, the scree test (Zwick \& Velicer,
The Me and My Disease Scale: measuring state hope 
1986; Zakrzewska, 1994) and the most accurate objective Standard Error Scree Test, as programmed by Watkins (2007; Canivez \& Watkins, 2010), indicated a one-factor solution. Since the scale was originally developed as a single latent factor accounting for hope, the single-factor model was retained for subsequent analysis. Therefore, EFA was conducted, imposing a preconceived one-factor structure on the outcome both for the total sample and for the different subgroups (see Table 2). The analysis included 9 out of 10 items with factor loadings above 0.50 (Zakrzewska, 1994). One item (Item 3) was deleted because its factor loading was lower than the required value.

\section{CONFIRMATORY FACTOR ANALYSIS}

The adequacy of the 9-item measurement model across the two subgroups was examined. For this purpose a two-group CFA by means of maximum likelihood (ML; Arbuckle, 2011) was performed using data from T2. As a result, the 4-item model was obtained (see Table 3), with the same pattern of factor loadings across subgroups, which were generally higher than 0.50 (the exception was Item 10). Common factoring showed $64.60 \%$ of the variance explained by a single factor (DM: 62.04\%, MI: 64.71\%). The modification index suggested that the fit indices of the model were acceptable if an error covariance was added between Items 9 and 10. Adding this error covariance also made sense from the substantive point of view since these items referred to hope as anticipating health improvements. The latter model showed good fit statistics for the entire group.

Significantly, the $\chi^{2}$ value was statistically significant, indicating a poor model fit, but this measure is sensitive to sample size (Arbuckle, 2011). However, the $\Delta \chi^{2}$ value (a statistic which minimises the impact of sample size on the model) achieved an acceptable ratio within the recommended range of 2 and 5 (see Hooper, Coughlan, \& Mullen, 2008).

The fit of the 4-item model was also assessed with the root mean square error of approximation $(\text { RMSEA })^{2}$. Here it fell below its recommended cut-off $(\leq .08)$, therefore showing a good fit for the total sample and the MI subgroup. Model fit as measured by RMSEA indicated poor fit for the DM subgroup with a lower than $90 \%$ confidence interval, in this case .059. In contrast, a sample of other fitness statistics such as GFI, TLI, AGFI, NFI and CFI achieved values above .90 , indicating acceptable fit for the data. Additionally, the scale displayed acceptable internal consistency reliability $\left[\alpha=.75_{(\mathrm{T} 1)}\right.$ and $.81_{(\mathrm{T} 2)}\left(\mathrm{DM}: .80_{(\mathrm{T} 1)}\right.$, $\left.\left..78_{(\mathrm{T} 2)}, \mathrm{MI}: .70_{(\mathrm{T} 1)}, .82_{(\mathrm{T} 2)}\right)\right]$.

\section{MEASUREMENT INVARIANCE}

The next step in the analysis was to test measurement invariance with multi-group CFAs using ML

Table 3

Standardized factor loadings and fit indices of CFA for entire sample and each subgroup

\begin{tabular}{|c|c|c|c|c|c|c|}
\hline & \multicolumn{2}{|c|}{ Entire sample $(n=510)$} & \multicolumn{2}{|c|}{ Diabetic $(n=287)$} & \multicolumn{2}{|c|}{ Cardiac $(n=232)$} \\
\hline & T1 & $\mathrm{T} 2$ & T1 & $\mathrm{T} 2$ & T1 & $\mathrm{T} 2$ \\
\hline Item 1 & .78 & .85 & .86 & .77 & .71 & .93 \\
\hline Item 2 & .79 & .86 & .92 & .93 & .62 & .79 \\
\hline Item 9 & .54 & .68 & .61 & .67 & .45 & .63 \\
\hline Item 10 & .45 & .42 & .43 & .39 & .53 & .41 \\
\hline $\operatorname{cov} 34$ & .27 & .35 & .26 & .19 & .36 & .51 \\
\hline$\chi^{2}(p)$ & $0.35(.557)$ & $3.92(.048)$ & $0.07(.785)$ & $6.87(.009)$ & $0.15(.698)$ & $1.20(.273)$ \\
\hline$\chi^{2} / d f$ & 0.35 & 3.92 & 0.07 & 6.87 & 0.15 & 1.20 \\
\hline RMR & .01 & .02 & .00 & .04 & .01 & .01 \\
\hline GFI & 1.00 & 1.00 & 1.00 & .99 & 1.00 & 1.00 \\
\hline TLI & 1.00 & .98 & 1.01 & .91 & 1.03 & 1.00 \\
\hline AGFI & 1.00 & .96 & 1.00 & .88 & 1.00 & .97 \\
\hline NFI & 1.00 & 1.00 & 1.00 & .98 & 1.00 & 1.00 \\
\hline CFI & 1.00 & 1.00 & 1.00 & .99 & 1.00 & 1.00 \\
\hline RMSEA & $\begin{array}{c}.00 \\
(.00 ; .10)^{\mathrm{a}}\end{array}$ & $\begin{array}{c}.08 \\
(.01 ; .16)^{\mathrm{a}}\end{array}$ & $\begin{array}{c}.00 \\
(.00 ; .10)^{\mathrm{a}}\end{array}$ & $\begin{array}{c}.15 \\
(.06 ; .26)^{\mathrm{a}}\end{array}$ & $\begin{array}{c}.00 \\
(.00 ; .13)^{\mathrm{a}}\end{array}$ & $\begin{array}{c}.03 \\
(.00 ; .18)^{\mathrm{a}}\end{array}$ \\
\hline
\end{tabular}

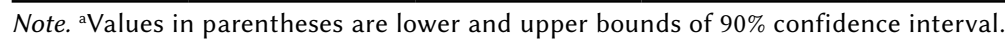


Table 4

Fit indices for measurement invariance models for the entire group and subgroups of disease: baseline (unconstrained), weak (measurement weights), strong (measurement intercept), and strict (measurement residual)

\begin{tabular}{|c|c|c|c|c|}
\hline $\begin{array}{c}\text { Goodness of fit and tests } \\
\text { of equivalence } \\
\text { of measurement model }\end{array}$ & Baseline & Weak & Strong & Strict \\
\hline Entire group, T1 vs. T2 & $\begin{aligned} \chi_{(2)}^{2} & =4.27 \\
\mathrm{CFI} & =.11 \\
\mathrm{TLI} & =1.02 \\
\mathrm{RMSEA} & =.00\end{aligned}$ & $\begin{aligned} \chi_{(5)}^{2} & =7.46 \\
\mathrm{CFI} & =.48 \\
\mathrm{TLI} & =1.01 \\
\mathrm{RMSEA} & =.00 \\
\Delta \chi_{(3)}^{2} & =3.19\end{aligned}$ & $\begin{aligned} \chi_{(9)}^{2} & =35.80 \\
\mathrm{CFI} & =14.65 \\
\mathrm{TLI} & =.73 \\
\mathrm{RMSEA} & =.17 \\
\Delta \chi_{(7)}^{2} & =31.53^{*}\end{aligned}$ & $\begin{aligned} \chi_{(15)}^{2} & =83.28 \\
\mathrm{CFI} & =16.02 \\
\mathrm{TLI} & =.71 \\
\mathrm{RMSEA} & =.17 \\
\Delta \chi_{(6)}^{2} & =79.01^{*}\end{aligned}$ \\
\hline Cardiac group, T1 vs. T2 & $\begin{aligned} \chi_{(2)}^{2} & =2.16 \\
\mathrm{CFI} & =1.00 \\
\mathrm{TLI} & =1.00 \\
\mathrm{RMSEA} & =.01\end{aligned}$ & $\begin{aligned} \chi_{(5)}^{2} & =7.89 \\
\mathrm{CFI} & =1.00 \\
\mathrm{TLI} & =1.00 \\
\mathrm{RMSEA} & =.03 \\
\Delta \chi_{(3)}^{2} & =5.73\end{aligned}$ & $\begin{aligned} \chi_{(9)}^{2} & =27.31 \\
\mathrm{CFI} & =.97 \\
\mathrm{TLI} & =.96 \\
\mathrm{RMSEA} & =.07 \\
\Delta \chi_{(4)}^{2} & =19.43^{*}\end{aligned}$ & $\begin{aligned} \chi_{(15)}^{2} & =119.35 \\
\mathrm{CFI} & =.83 \\
\mathrm{TLI} & =.85 \\
\mathrm{RMSEA} & =.12 \\
\Delta \chi_{(6)}^{2} & =92.03^{*}\end{aligned}$ \\
\hline Diabetic group, T1 vs. T2 & $\begin{aligned} \chi_{(2)}^{2} & =6.95 \\
\mathrm{CFI} & =.99 \\
\mathrm{TLI} & =.97 \\
\mathrm{RMSEA} & =.07\end{aligned}$ & $\begin{aligned} \chi_{(5)}^{2} & =11.62 \\
\mathrm{CFI} & =.99 \\
\mathrm{TLI} & =.98 \\
\mathrm{RMSEA} & =.05 \\
\Delta \chi_{(3)}^{2} & =4.67\end{aligned}$ & $\begin{aligned} \chi_{(9)}^{2} & =35.29 \\
\mathrm{CFI} & =.97 \\
\mathrm{TLI} & =.96 \\
\mathrm{RMSEA} & =.07 \\
\Delta \chi_{(4)}^{2} & =23.67^{*}\end{aligned}$ & $\begin{aligned} \chi_{(15)}^{2} & =42.23 \\
\mathrm{CFI} & =.97 \\
\mathrm{TLI} & =.94 \\
\mathrm{RMSEA} & =.06 \\
\Delta \chi_{(6)}^{2} & =6.94\end{aligned}$ \\
\hline Cardiac vs. Diabetic, T1 & $\begin{aligned} \chi_{(2)}^{2} & =.89 \\
\mathrm{CFI} & =1.00 \\
\mathrm{TLI} & =1.01 \\
\mathrm{RMSEA} & =.00\end{aligned}$ & $\begin{aligned} \chi_{(5)}^{2} & =4.11 \\
\mathrm{CFI} & =1.00 \\
\mathrm{TLI} & =1.00 \\
\mathrm{RMSEA} & =.00 \\
\Delta \chi_{(3)}^{2} & =3.22\end{aligned}$ & $\begin{aligned} \chi_{(9)}^{2} & =132.01 \\
\mathrm{CFI} & =.80 \\
\mathrm{TLI} & =.74 \\
\mathrm{RMSEA} & =.17 \\
\Delta \chi_{(4)}^{2} & =127.89^{*}\end{aligned}$ & $\begin{aligned} \chi_{(15)}^{2} & =247.27 \\
\mathrm{CFI} & =.63 \\
\mathrm{TLI} & =.70 \\
\mathrm{RMSEA} & =.18 \\
\Delta \chi_{(6)}^{2} & =115.26^{*}\end{aligned}$ \\
\hline Cardiac vs. Diabetic, T2 & $\begin{aligned} \chi_{(2)}^{2} & =8.22 \\
\mathrm{CFI} & =.99 \\
\mathrm{TLI} & =.95 \\
\mathrm{RMSEA} & =.08\end{aligned}$ & $\begin{aligned} \chi_{(5)}^{2} & =15.33 \\
\mathrm{CFI} & =.99 \\
\mathrm{TLI} & =.97 \\
\mathrm{RMSEA} & =.06 \\
\Delta \chi_{(3)}^{2} & =7.11 \\
p & =.069\end{aligned}$ & $\begin{aligned} \chi_{(9)}^{2} & =203.86 \\
\mathrm{CFI} & =.75 \\
\mathrm{TLI} & =.67 \\
\mathrm{RMSEA} & =.21 \\
\Delta \chi_{(4)}^{2} & =188.50^{*}\end{aligned}$ & $\begin{aligned} \chi_{(15)}^{2} & =240.16 \\
\mathrm{CFI} & =.71 \\
\mathrm{TLI} & =.77 \\
\mathrm{RMSEA} & =.17 \\
\Delta \chi_{(6)}^{2} & =36.30^{*}\end{aligned}$ \\
\hline
\end{tabular}

Note. CFI - comparative fit ind
1 and 2 respectively, ${ }^{*} p=.05$.

estimation (see Table 4). This method examines whether a latent variable is related to the items in the same way for all groups so that progressively constrained additional sets of parameters are expected to be equal across the subgroups. Testing measurement invariance where constraints to the models are added consecutively occurs in the following ways: (1) the unconstrained model (baseline model) with one-factor loading constrained to unity; (2) the weak (metric) model which constrains the factor loadings so that they are equal across groups; (3) the strong (scalar) model which constrains the factor loadings and intercepts, making them equal across groups; and (4) the strict model which additionally constrains the residuals (cf. Arbuckle, 2011).

It was estimated that the scale measured the same construct in the same way over a period of time (T1 vs. T2 in entire group and subgroups) for all of the examined clinical groups (T1: MI vs. DM, T2: MI vs. DM). Results from factorial invariance in the total sample and in the subgroups showed that factor loadings could be constrained to equality between phases, therefore indicating weak invariance $\left[\Delta \chi_{(3)}^{2}=3.19, p=.363\right]$. Further testing also indicated invariance at a weak level between phases in the clinical subgroups [MI: $\Delta \chi_{(3)}^{2}=5.73, p=.203$, DM: $\left.\Delta \chi_{(3)}^{2}=4.67, p=.198\right]$ and across subgroups [MI vs. DM, T1: $\Delta \chi_{(3)}^{2}=3.22, p=.537, \mathrm{~T} 2: \Delta \chi_{(3)}^{2}=7.11$, $p=.069]$.

In summary, a single-factor structure consisting of 4 items provided good fit on all fitness indices for the entire sample and for the MI subgroup. One of the fitness indices (in this case RMSEA) was above the recommended cut-off value $(\leq .08)$. Simultaneously, the results of the tests for multi-group invariance between phases and subgroups showed weak invariance as shown by significant differences in $\Delta \chi^{2}$. This indicates a consistent factor loading in the latent variable across the subgroups and over time, which also enables analysis involving comparisons
The Me and My Disease Scale: measuring state hope 
of means between the groups and correlations with the latent variable.

\section{CONSTRUCT VALIDITY}

Testing of construct validity was conducted by analysis of correlations between state hope, cognitive appraisal and emotion for all the subgroups. To test divergent validity, the relationships between state hope and depressive symptoms among patients after MI $(n=150)$ were explored. The results of correlations between variables are shown in Table 5. The results confirm the anticipated correlations between the variables.

The sample demonstrates weak synchronic correlations between hope and threat/loss (T2) and optimism/passivity (T1 and T2) cognitive appraisal as well as negative emotions (T2). Furthermore, moderate positive relationships between hope and challenge/activity (T1 and T2) cognitive appraisal and positive emotions (T1 and T2) were noted. The same results were obtained in both clinical subgroups with the exception of a lack of correlation between hope and optimism/passivity cognitive appraisal and negative emotions among patients after MI. Moreover, weak and moderate negative correlations between hope and depression symptoms (BDI) were observed in this clinical subgroup. In conclusion, correlation analysis revealed weak or moderate connections between hope and other variables, explaining $1-16 \%$ of the variance of state hope.

\section{ILLNESS TYPE AS MODERATOR OF CHANGE IN HOPE}

The next step in the analysis was to test whether stress levels experienced in the course of two different chronic diseases moderate changes in state hope. Therefore, differences between changes in state hope over time in two subgroups were presented on the grounds of interaction effects. A two-way interaction effect between Illness and Time repeated-measure analysis of variance was conducted for pooled data. In addition, significant confounding variables, gender and marital status (recoded), were also included as covariates in subsequent analysis.

Type of illness turned out to moderate changes in state hope (a significant interaction effect of Illness and Time; $F(1,496)=14.86, p=.001$, partial $\left.\eta^{2}=.03\right)$. State hope decreased over time in the DM group $\left(p=.002\right.$, partial $\left.\eta^{2}=.04\right)$ but remained at the same level in the MI group ( $p=.344$ ) (see Figure 1). Moreover, the results revealed a significant main effect for Illness: the MI group experienced a higher level of state hope than the DM group regardless of the phase examined $\left(F(1,496)=50.26, p=.001\right.$, partial $\left.\eta^{2}=.09\right)$. The main effect for time after the inclusion of significant socio-demographic variables was not significant $(F(1$, $496)=1.96, p=.162$, partial, $p=$ n.s.). In contrast, the results of ANOVA comparing state hope between the clinical subgroups (MI vs. DM) separately for each phase of the study showed significant effects for Illness

Table 5

Correlation between HOPE scale with cognitive appraisal, emotions (Diabetic and Cardiac patients) and depression (only Cardiac patients).

\begin{tabular}{ccccccc}
\hline & \multicolumn{2}{c}{ Entire sample } & \multicolumn{2}{c}{ Diabetic patients } & \multicolumn{2}{c}{ Cardiac patients } \\
\cline { 2 - 6 } & HOPE 1 & HOPE 2 & HOPE 1 & HOPE 2 & HOPE 1 & HOPE 2 \\
\hline TLCA T1 & .01 & .03 & $-.16^{* *}$ & $-.14^{*}$ & $.18^{* *}$ & .08 \\
TLCA T2 & -.08 & $-.21^{* *}$ & -.10 & $-.26^{* *}$ & -.01 & .10 \\
Ch/ACA T1 & $.29^{* *}$ & $.18^{* *}$ & $.28^{* *}$ & $.19^{* *}$ & $.31^{* *}$ & $.18^{* *}$ \\
Ch/ACA T2 & $.25^{* *}$ & $.34^{* *}$ & $.17^{* *}$ & $.31^{* *}$ & $.31^{* *}$ & $.31^{* *}$ \\
O/PCA T1 & $.20^{* *}$ & $.17^{* *}$ & $.20^{* *}$ & $.16^{* *}$ & .11 & .02 \\
O/PCA T2 & .05 & $.21^{* *}$ & -.05 & $.24^{* *}$ & .11 & .09 \\
PA T1 & $.30^{* *}$ & $.15^{* *}$ & $.33^{* *}$ & $.17^{* *}$ & $.31^{* *}$ & $.21^{* *}$ \\
PA T2 & $.26^{* *}$ & $.34^{* *}$ & $.20^{* *}$ & $.36^{* *}$ & $.37^{* *}$ & $.40^{* *}$ \\
NA T1 & .06 & .00 & $-.12^{*}$ & $-.19^{* *}$ & $.28^{* *}$ & $.19^{* *}$ \\
NA T2 & $-.10^{*}$ & $-.23^{* *}$ & -.06 & $-.26^{* *}$ & -.09 & .10 \\
BDI T1 & - & - & - & - & $-.37^{* *}$ & $-.21^{*}$ \\
BDI T2 & - & - & - & $-.19^{*}$ & $-.17^{*}$ \\
\hline
\end{tabular}

Note. TLCA - threat/loss cognitive appraisal, Ch/ACA - challenge/activity cognitive appraisal, O/PCA - optimism/passivity cognitive appraisal, PA - positive affect, NA - negative affect, BDI - symptoms of depression. T1 and T2 - time 1 and 2 respectively. ${ }^{*} p<.05,{ }^{* *} p<.01$. 
(T1: $M_{\mathrm{MI}}=15.70, S D_{\mathrm{MI}}=3.50, M_{\mathrm{DM}}=14.08, S D_{\mathrm{DM}}=3.85$, $F_{1}(1,502)=24.07, p<.001 ; \mathrm{T} 2: M_{\mathrm{MI}}=15.96, S D_{\mathrm{MI}}=3.55$, $\left.M_{\mathrm{DM}}=13.10, S D_{\mathrm{DM}}=3.63, F(1,500)=78.07, p<.001\right)$.

\section{DISCUSSION AND CONCLUSIONS}

The first aim of the study was to construct and assess the factorial validity of the state hope scale for patients with chronic diseases. The analysis was conducted in two clinical groups: the first one consisting of people after myocardial infarction and the second composed of type 2 diabetes patients. The results of EFA showed a unidimensional structure for the state hope scale which was in line with the employed definition of hope. CFA showed that the 4-item scale ("I have many plans for the future"; "My plans are very likely to be achieved"; "Regardless of my illness, I will achieve my goals"; "There is a high chance that I will get well”) was characterized by satisfactory internal consistency reliability coefficients and fit indices both for the whole sample and for the MI subgroup. The exception was the slightly worse model fit when RMSEA was used for the DM group, providing a modestly acceptable fit for the data and therefore demonstrating that hope does not have the same meaning for diabetic patients-this shows that the underlying construct is not fully comparable across clinical groups (especially in relation to Item 10). Furthermore, the analysis points to a weak measurement equivalence for the scale, for the whole sample as well as for each group during both phases of the research, in which the factor loadings of the items in the latent construct are held to be equivalent across the clinical groups. This effect indicates the sensitivity of the scale to the type and course of illness. The results discussed in this paper allow for the comparison of relationships to hope and other variables across clinical groups at various stages of illness, but caution should be used when examining the means of latent variables (Borsboom, 2006).

The individual item content analysis suggests that the scale is agreeable to the cognitive approach (i.e. defining hope as the expectation of goal attainment and recovery). Consequently, the scale relates to hope conceptualized in terms of Snyder's "agency thinking”, which, according to other researchers (see Tong et al., 2010), is an expectation that desired goals can somehow be attained regardless of an individual's self-perceived capability of achieving those aims. Such an understanding of hope is akin to its colloquial definition (Tong et al., 2010).

However, relatively low factor loadings for Items 9 and 10 were achieved in relation to the phenomenon described as "disease specific hope" (i.e. hoping to achieve goals regardless of illness and hope of recovery), in contrast to "generic hope" (hoping to achieve one's plans).

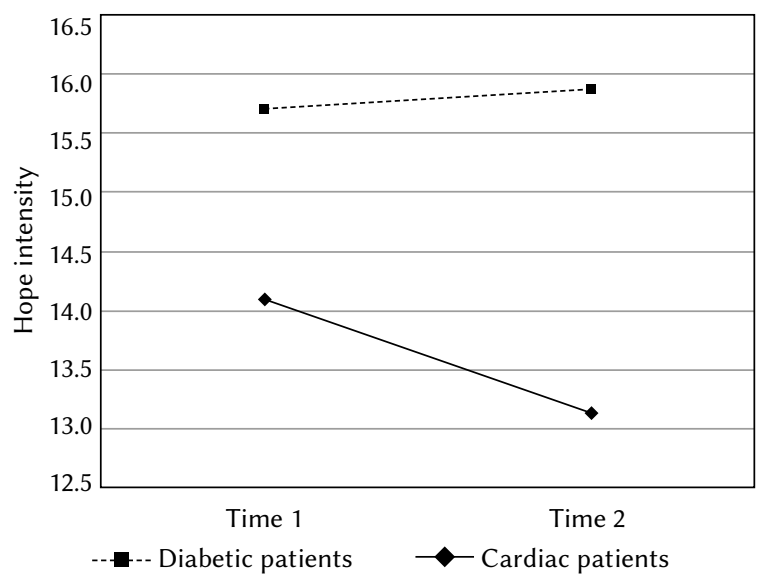

Figure 1. Interactions between Illness and Time on hope.

Note. Covariates appearing in the model are evaluated at the following values: gender $=.71$, age $=50.78$, education $=.62$, marital status $=1.82$, employment $=.61$.

The results of the study may indicate that hope in the context of illness is closely related to the specific course of the illness, and, as a consequence, may be perceived differently by patients at different stages of a given illness. At the same time, it is worth emphasizing that the tool was meant to assess state hope in different situational contexts.

The analysis of the theoretical validity of the scale demonstrated anticipated correlations between hope and cognitive appraisal, emotion and depressive symptoms (but only for MI). The moderate relationships between hope and these variables confirmed the scale's theoretical validity. Furthermore, there was no item overlap between scales. The Me and My Disease Scale, as a measure of state hope, differs from other measures of positive and negative cognitive appraisal and adjustment indicators (emotions and depressive symptoms).

Additional analysis shows that the type of illness was a significant moderator of changes in hope over periods of time. The obtained results show different levels of hope in the two clinical groups, which suggests its dependency on the course of illness and, consequently, stress intensity. Over the course of time, patients who experienced MI became better as the imminent risk of death diminished, yet this did not affect their levels of hope. On the other hand, the introduction of insulin therapy for diabetes patients was a signal that their illness could not be reversed and that it was progressing. This led to a decrease in state hope. As mentioned, the unsatisfactory model fit might be explained by the different item interpretation. In particular, Item 10, which referred to hope for recovery, refers to something which is impossible in the case of diabetes.

This study has certain limitations. When measuring the theoretical validity of the scale, one should include other hope measurement tools - such as the
The Me and My Disease Scale: measuring state hope 
one proposed by Snyder et al. (1996) or by Trzebiński and Zięba (2004; the Basic Hope Inventory). At the same time, the strength of this study lies in the sample size and in the choice of the clinical trial groups.

Taking all results into account, one can argue that the Me and My Disease Scale is characterized by good psychometric properties - structure, reliability and validity - and thus may be used to measure state hope in patients for the purpose of scientific research. The greatest weakness of the scale is its weak time and group invariance. However, this is a problem for several measurements, even those measuring traits as opposed to states. Further studies should focus on testing the scale in relation to patients suffering from other chronic somatic diseases in order to clarify the statistical significance of the scale.

\section{ENDNOTES}

1 Because of the specific character of the sample, exploratory as well as confirmatory factor analysis was conducted for all measures. Measurement invariance was established for two subscales with 12 items each and this version was used in further analysis.

2 Suggested values of fit statistics: $\chi^{2} / d f=<2-5>$, RMR close to $0, \mathrm{TLI}>.95, \mathrm{AGI} \geq .90 ; \mathrm{GFI} \geq .90, \mathrm{NFI} \geq .95$, $\mathrm{CFI} \geq .95$, RMSEA $\leq .05$ (Arbuckle, 2011).

\section{ReFERENCES}

Ai, A. L., Park, C., Huang, B., Rodgers, W., \& Tice, T. N. (2007). Psychosocial mediation of religious coping: A prospective study of short-term psychological distress after cardiac surgery. Personality and Social Psychology Bulletin, 33, 867-882. DOI: 10.1177/0146167207301008

Ai, A. L., Tice, T. N., Whitsett, D. D., Ishisaka, T., \& Chim, M. (2007). Posttraumatic symptoms and growth of Kosovar war refugees: The influence of hope and cognitive coping. The Journal of Positive Psychology, 2, 55-65. DOI: 10.1080/17439760601069341

Ai, A. L., Wink, P., \& Shearer, M. (2012). Fatigue of survivors following cardiac surgery: Positive influences of preoperative prayer coping. British Journal of Health Psychology, 17, 724-742. DOI: 10.1111/j.2044-8287.2012.02068.x

Arbuckle, J. L. (2011). Amos 20.0. User's Guide. Amos Development Corporation, SPSS Inc.

Beck, A. T., Ward, C. H., Mendelson, M., Mock, J., \& Erbaugh, J. (1961). An inventory for measuring depression. Archives of General Psychiatry, 4, 5363. DOI: 10.1001/archpsyc. 1961.01710120031004

Borsboom, D. (2006). When does measurement invariance matter? Medical Care, 44, 176-181. DOI: 10.1097/01.mlr.0000245143.08679.cc
Bruininks, P., \& Malle, B. F. (2005). Distinguishing hope from optimism and related affective states. Motivation and Emotion, 29, 327-355. DOI: 10.1007/ s11031-006-9010-4

Brzozowski, P. (2010). Skala uczuć pozytywnych i negatywnych SUPIN: polska adaptacja skali PANAS Davida Watsona i Lee Anny Clark: podręcznik [Positive and negative affect scale SUPIN: Polish adaptation of PANAS David Watson and Ann Lee Clark. Manual]. Warsaw: Pracownia Testów Psychologicznych Polskiego Towarzystwa Psychologicznego.

Canivez, G. L., \& Watkins, M. W. (2010). Investigation of the factor structure of the Wechsler Adult Intelligence Scale-Fourth Edition (WAIS-IV): Exploratory and higher-order factor analyses. Psychological Assessment, 22, 827-836. DOI: 10.1037/ a0020429

Chang, E. C., \& DeSimone, S. L. (2001). The influence of hope on appraisals, coping, and dysphoria: a test of hope theory. Journal of Social and Clinical Psychology, 20, 117-129. DOI: 10.1521/ jscp.20.2.117.22262

Coyne, J. C., Stefanek, M., \& Palmer, S. C. (2007). Psychotherapy and Survival in Cancer: The Conflict Between Hope and Evidence. Psychological Bulletin, 133, 367-394. DOI: 10.1037/0033-2909.133.3.367

Drach-Zahavy, A., \& Somech, A. (2002) Coping with health problems: The distinctive relationships of Hope sub-scales with constructive thinking and resource allocation. Personality and Individual Difference, 33, 103-117. DOI: 10.1016/S01918869(01)00138-6

Folkman, S. (1997). Positive psychological states and coping with severe stress. Social Science and Medicine, 45, 1207-1221. DOI: 10.1016/S02779536(97)00040-3

Folkman, S. (2008). The case for positive emotions in the stress process. Anxiety, Stress, \& Coping, 21, 3-14. DOI: $10.1080 / 10615800701740457$

Folkman, S. (2010). Stress, coping, and hope. Psycho-Oncology, 19, 901-908. DOI: 10.1002/pon.1836

Folkman, S., \& Lazarus, R. S. (1985). If it changes it must be a process: study of emotion and coping during three stages of a college examination. Journal of Personality and Social Psychology, 48, 150170. DOI: 10.1037/0022-3514.48.1.150

Frankl, V. (1984). Man's Search For Meaning. Washington: Washington Square Press.

Gum, G., \& Snyder, C. R. (2002). Coping with terminal illness: the role of hopeful thinking. Journal of Palliative Medicine, 5, 883-894. DOI: 10.1089/10966210260499078

Hassija, C. M., Luterek, J. A., Naragon-Gainey, K., Moore, S. A., \& Simpson, T. L. (2012). Impact of emotional approach coping and hope on PTSD and depression symptoms in a trauma exposed sample of veterans receiving outpatient VA men- 
tal health care services. Anxiety, Stress, \& Coping, 25, 559-573. DOI: 10.1080/10615806.2011.621948

Hasson-Ohayon, I., Braun, M., Galinsky, D., \& Baider, L. (2009). Religiosity and hope: A path for women coping with a diagnosis of breast cancer. Psychosomatics, 50, 525-533. DOI: 10.1037/t00088-000

Heszen, I. (2012). Temperament and coping activity under stress of changing intensity over time. European Psychologist, 17, 326-336. DOI: 10.1027/10169040/a000121

Heszen-Niejodek, I., Gottschalk, L., \& Januszek, M. (1999). Anxiety and hope during the course of three different medical illnesses: A longitudinal study. Psychotherapy and Psychosomatics, 68, 304312. DOI: $10.1159 / 000012348$

Hooper, D., Coughlan, J., \& Mullen, M. R. (2008). Structural equation modelling: Guidelines for determining model fit. The Electronic Journal of Business Research Methods, 6, 53-60.

Kennedy, P., Evans, M., \& Sandhu, N. (2009). Psychological adjustment to spinal cord injury: the contribution of coping, hope and cognitive appraisals. Psychology, Health and Medicine, 14, 17-33. DOI: 0.1080/13548500802001801

Kristofferzon, M.-L., Löfmark, R., \& Carlsson, M. (2008). Managing consequences and finding hope - experiences of Swedish women and men 4-6 months after myocardial infarction. Scandinavian Journal of Caring Sciences, 22, 367-375. DOI: 10.1111/j.1471-6712.2007.00538.x

Lazarus, R. S. (1991). Progress on a cognitive-motivational-relational theory of emotion. American Psychologist, 46, 819-834.

Lazarus, R. S. (1999). Hope: An emotion and a vital coping resource against despair. Social Research, 66, 653-678.

Lazarus, R. S. (2006). Emotions and interpersonal relationships: Toward a person-centered conceptualization of emotions and coping. Journal of Personality, 74, 9-46. DOI: 10.1111/j.1467-6494.2005.00368.x

Ong, A. D., Edwards, L. M., \& Bergeman, C. S. (2006). Hope as a source of resilience in later adulthood. Personality and Individual Differences, 41, 12631273. DOI: 10.1016/j.paid.2006.03.028

Parnowski, T., \& Jernajczyk, W. (1977). Inwentarz Depresji Becka w ocenie nastroju osób zdrowych i chorych na choroby afektywne (ocena pilotażowa) [Beck Depression Inventory in assessing mood in healthly subjects and patients with affective disorders. Pilot study]. Psychiatria Polska, 11, 417-421.

Rabkin, J. G., McElhiney, M., Moran, P., Acree, M., \& Folkman, S. (2009). Depression, distress and positive mood in late-stage cancer: a longitudinal study. Psycho-Oncology, 18, 79-86. DOI: 10.1002/pon.1386

Roesch, S. C., Duangado, K. M., Vaughn, A. A., Aldridge, A. A., \& Villodas, F. (2010). Dispositional hope and the propensity to cope: A daily diary as- sessment of minority adolescents. Cultural Diversity And Ethnic Minority Psychology, 16, 191-198. DOI: $10.1037 / \mathrm{a} 0016114$

Snyder, C. R. (2002). Hope theory: Rainbows in the mind. Psychological Inquiry, 13, 249-275.

Snyder, C. R., Harris, C., Anderson, J. R., Holleran, S. A., Irving, L. M., Sigmon, S. T., Yoshinobu, L., Gibb, J., Langelle, C., \& Harney, P. (1991). The will and the ways: Development and validation of an individual-differences measure of hope. Journal of Personality and Social Psychology, 60, 570-585.

Snyder, C. R., Sympson, S. C., Ybasco, F. C., Borders, T. F., Babyak, M. A., \& Higgins, R. L. (1996). Development and validation of the State Hope Scale. Journal of Personality and Social Psychology, 70, 321-335. DOI: 10.1037/0022-3514.70.2.321

Soundy, A., Smith, B., Dawes, H., Pall, H., Gimbrere, K., \& Ramsay, J. (2011). Patients expression of hope and illness narratives in three neurological conditions: a meta-ethnography. Health Psychology Review, 7, 1-25. DOI: 10.1080/17437199.2011.568856

Stanton, A. L., Danoff-Burg, S., \& Huggins, M. E. (2002). The first year after breast cancer diagnosis: Hope and coping strategies as predictors of adjustment. Psycho-Oncology. Special Issue: Survivorship, 11, 93-102. DOI: 10.1002/pon.574

Steffen, L. E., \& Smith, B. W. (2013). The influence of between and within-person hope among emergency responders on daily affect in a stress and coping model. Journal of Research in Personality, 47, 738-747.

Tong, E. M. W., Fredrickson, B. L., Chang, W. C., \& Lim, Z. X. (2010). Re-examining hope: The roles of agency thinking and pathways thinking. Cognition and Emotion, 24, 1207-1215. DOI: 10.1080/02699930903138865

Trzebiński, J., \& Zięba, M. (2004). Basic Hope as a World-View. Polish Psychological Bulletin, 35, 173-182.

Watkins, M. W. (2007). SEscree [Computer soft-ware]. State College, PA: Ed \& Psych Associates. http:// edpsychassociates.com/Watkins3.html

Watson, D., Clark, L. A., \& Tellegen, A. (1988). Development and validation of brief measures of positive and negative affect: the PANAS Scales. Journal of Personality and Social Psychology, 54, 1063-1070

Włodarczyk, D., \& Wrześniewski, K. (2010). Kwestionariusz Oceny Stresu [The Stress Appraisal Questionnaire]. Przeglad Psychologiczny, 53, 479-496.

Zakrzewska, M. (1994). Analiza czynnikowa w budowaniu i sprawdzaniu modeli psychologicznych [Factor analysis in building and verifying the psychological models]. Poznan: Wydawnictwo $\mathrm{Na}$ ukowe UAM.

Zwick, W. R., \& Velicer, W. F. (1986). Comparison of five rules for determining the number of components to retain. Psychological Bulletin, 99, 432-442.
The Me and My Disease Scale: measuring state hope 